\title{
KEMAMPUAN KOMUNIKASI MATEMATIS DAN \\ PEMECAHAN MASALAH MELALUI PROBLEM BASED-LEARNING
}

\author{
Fatia Fatimah \\ UPBJJ-UT Padang \\ fatia@ut.ac.id
}

\begin{abstract}
Abstrak
Tujuan penelitian untuk mengetahui kemampuan komunikasi matematis dan pemecahan masalah melalui Problem Based Learning (PBL). Populasi penelitian adalah mahasiswa STKIP PGRI Sumatera Barat yang mengambil mata kuliah Statistika Elementer tahun akademik 2008/2009. Jenis penelitan adalah eksperimen semu dengan pretest-postest control group design. Kelompok eksperimen diberi perlakuan berupa pembelajaran dengan model Problem Based Learning dan kelompok kontrol dengan pembelajaran biasa. Data dikumpulkan melalui worksheet, rubrik presentasi, assesmen investigasi dan tes hasil belajar Statistika Elementer. Hasil analisis data menunjukkan bahwa 1) kemampuan komunikasi matematis mahasiswa dengan menerapkan model PBL dalam pembelajaran Statistika Elementer tidak lebih baik dibandingkan dengan pembelajaran biasa, 2) kemampuan pemecahan masalah mahasiswa dengan menerapkan model PBL dalam pembelajaran Statistika Elementer lebih baik dibandingkan dengan pembelajaran biasa.
\end{abstract}

Kata kunci: komunikasi matematis, pemecahan masalah, problem based learning 


\title{
COMMUNICATION SKILLS AND PROBLEM SOLVING THROUGH MATHEMATICAL PROBLEM-BASED LEARNING
}

\author{
Fatia Fatimah \\ UPBJJ-UT Padang \\ fatia@,ut.ac.id
}

\begin{abstract}
The purpose of this research is to know the mathematic communicative competence and problem solving competence through problem based learning (PBL). This research was done to students of STKIP PGRI West Sumatera who were studying Statistica Elementer subject in 2008/2009 academic year. This research was quasi experimental research. The design of this research was pretest-postest control group. PBL model was given to experimental group and conventional learning was done on control group. Data were collected through worksheet, presentation rubric, investigation assessment, and achievement test of Statistica Elementer subject. Data analysis shows that 1) students implementing PBLbetter do not show mathematic communicative competence than those implementing conventional learning. 2) students who used PBL model show better ability on problem solving than those using conventional learning.
\end{abstract}

Keywords: communication of mathematic, problem solving, problem based learning 


\section{Pendahuluan}

Kemampuan komunikasi matematis dan pemecahan masalah penting untuk dikuasai oleh mahasiswa. Hal ini dikarenakan masyarakat membutuhkan kaum intelektual yang mampu menyelesaikan masalah secara sistematis dan mampu untuk menginterpretasikan ke dalam bahasa lisan maupun tulisan yang mudah dipahami. Perguruan tinggi sebagai wadah pendidikan formal terakhir diharapkan dapat memfasilitasi berkembangnya kemampuan komunikasi matematis dan pemecahan masalah mahasiswa.

Problem based learning (PBL) sebagai salah satu model pembelajaran memiliki ciri khas yaitu selalu dimulai dan berpusat pada masalah. Di dalam PBL para mahasiswa dapat bekerja di dalam kelompok-kelompok kecil dan harus mengidentifikasi apa yang mereka ketahui serta apa yang mereka tidak ketahui dan harus belajar untuk memecahkan suatu masalah. Peran utama dari dosen untuk memudahkan proses kelompok dan belajar, bukan untuk menyediakan jawaban secara langsung.

Beberapa penelitian tentang PBL dalam pembelajaran matematika/statistika diperoleh hasil yang positif (Wagiran, 2007; Dina, 2008). Akan tetapi penelitian yang sekaligus melihat kemampuan komunikasi matematis dan pemecahan masalah melalui PBL pada statistika belum dilakukan. Sementara itu, penelitian yang terkait dengan kemampuan komunikasi matematis masih terdapat hasil yang kurang memuaskan (Firdaus, 2005).

Berdasarkan observasi awal terhadap mahasiswa matematika STKIP PGRI Sumbar yang mengambil matakuliah Statistika Elementer diperoleh temuan bahwa mahasiswa kurang mampu dalam memecahkan masalah matematika yang terkait dengan dunia nyata dan belum terbiasa menuangkan pemikiran dalam bentuk lisan maupun tulisan. Mereka kesulitan dalam menentukan masalah, tahapan yang harus dipilih untuk mencari solusi serta menentukan pola yang dapat digunakan. Mahasiswa lebih senang jika diberikan soal berbentuk simbol dan angka-angka sehingga langsung tahu apa yang akan dicari tanpa harus menginterpretasikan soal terlebih dahulu. Pertanyaan tentang "kenapa" 
paling sulit untuk dijawab. Mahasiswa beralasan, "tahu jawabannya namun susah untuk diutarakan".

Tujuan penelitian adalah untuk mengetahui apakah kemampuan komunikasi matematis mahasiswa melalui PBL dalam pembelajaran Statistika Elementer lebih baik dari kemampuan komunikasi matematis mahasiswa dengan pembelajaran biasa dan mengetahui apakah kemampuan pemecahan masalah mahasiswa melalui PBL dalam pembelajaran Statistika Elementer lebih baik dari kemampuan pemecahan masalah mahasiswa dengan pembelajaran biasa.

\section{Metode Penelitian}

Penelitian menggunakan pretest-postest control group design. Populasi penelitian adalah mahasiswa program studi pendidikan matematika STKIP PGRI Sumatera Barat yang mengambil mata kuliah Statistika Elementer pada tahun akademik 2008/2009. Teknik pengambilan sampel adalah purposive sampling. Pengukuran kemampuan komunikasi matematis dan pemecahan masalah diambil dari worksheet dan tes hasil belajar serta menggunakan rubrik untuk menilai presentasi, assesmen investigasi.

PBL dalam penelitian ini dilakukan secara berkelompok dengan teknik pertanyaan studi terbuka dan tertutup. Tahap-tahap pelaksanaan PBL menerapkan prosedur yang dikemukakan oleh Ronnis (2000) yaitu: 1. Determining whether a problem exists, 2. Creating an exact statement of the problem, 3. Identifying information needed to understand the problem, 4. Identifying resources for gathering information, 5. Generating possible solutions, 6. Analyzing the solutions, 7. Presenting the solution, orally and/ or in writing.

Kemampuan komunikasi matematis dan pemecahan masalah diukur tidak hanya menggunakan soal tes essay akan tetapi juga melalui lembar kerja (worksheet) dan menggunakan assesmen presentasi dan investigasi. Soal tes essay dibuat dengan mengacu pada indikator komunikasi matematis dan pemecahan masalah.

Indikator komunikasi matematis pada soal tes adalah menyajikan pernyataan matematika secara lisan, tertulis, gambar dan diagram, mengajukan dugaan, melakukan manipulasi matematika, menarik 
kesimpulan, menyusun bukti, memberikan alasan atau bukti terhadap kebenaran solusi. Indikator kemampuan pemecahan masalah pada soal tes adalah menunjukkan pemahaman masalah /memformulasi masalah, mengorganisasi data dan memilih informasi yang relevan dalam pemecahan masalah, menyajikan masalah secara matematik dalam berbagai bentuk, memilih pendekatan dan metode pemecahan masalah secara tepat, mengembangkan strategi pemecahan masalah, membuat dan menafsirkan model matematika dari suatu masalah.

Indikator worksheet yang digunakan adalah kemampuan menuliskan permasalahan dengan bahasa sendiri, kemampuan mengembangkan solusi terkait permasalahan, dan kemampuan mengkaji ulang solusi. Indikator rubrik presentasi adalah kebenaran konsep yang dijelaskan mahasiswa, mendiskripsikan dan menjelaskan secara detail, kedalaman argumentasi mahasiswa, dan kebenaran membuat kesimpulan. Indikator rubrik assesmen investigasi adalah kemampuan memahami permasalahan dan konsep pembelajaran, kemampuan menggunakan strategi investigasi, kemampuan mengemukakan ide dalam bentuk laporan tertulis, dan kebenaran membuat kesimpulan. Pedoman penskoran worksheet dan rubrik menggunakan kategori sebagai berikut, 4: sangat baik, 3: baik, 2: cukup, dan 1: kurang.

\section{Hasil dan Pembahasan}

Berdasarkan hasil olahan data worksheet untuk setiap kelompok selama lima kali pertemuan (Tabel 1) diperoleh hasil bahwa tiga kelompok terkategori baik untuk kemampuan komunikasi matematis dan selebihnya masih kurang. Kemampuan pemecahan masalah untuk keempat kelompok terkategori baik dan sisanya kurang.

Skor rubrik setiap kelompok untuk lima kali pertemuan dan rataratanya dapat dilihat pada Tabel 2. Berdasarkan Tabel 2 dapat diketahui bahwa kemampuan komunikasi secara berkelompok mengalami peningkatan dan secara rata-rata terkategori baik. Kemampuan pemecahan masalah secara berkelompok terkategori baik. 
Tabel 1. Skor worksheet untuk setiap kelompok

\begin{tabular}{|c|c|c|c|c|c|c|c|c|c|c|c|c|}
\hline Kel. & \multicolumn{5}{|c|}{$\begin{array}{c}\text { Komunikasi } \\
\text { matematis }\end{array}$} & $\begin{array}{l}\text { rata- } \\
\text { rata }\end{array}$ & \multicolumn{5}{|c|}{$\begin{array}{c}\text { Pemecahan } \\
\text { Masalah }\end{array}$} & $\begin{array}{l}\text { rata- } \\
\text { rata }\end{array}$ \\
\hline & 1 & 2 & 3 & 4 & 5 & & 1 & 2 & 3 & 4 & 5 & \\
\hline 1 & 1 & 1 & 2 & 2 & 3 & 1,8 & 2 & 3 & 4 & 4 & 4 & 3,4 \\
\hline 2 & 3 & 1 & 3 & 3 & 3 & 2,6 & 1 & 2 & 3 & 3 & 3 & 2,4 \\
\hline 3 & 1 & 3 & 4 & 4 & 4 & 3,2 & 1 & 2 & 3 & 3 & 3 & 2,4 \\
\hline 4 & 3 & 3 & 3 & 3 & 4 & 3,2 & 2 & 2 & 3 & 4 & 4 & 3 \\
\hline 5 & 1 & 3 & 3 & 4 & 4 & 3 & 2 & 3 & 3 & 3 & 4 & 3 \\
\hline 6 & 1 & 1 & 4 & 4 & 4 & 2,8 & 2 & 3 & 4 & 4 & 4 & 3,4 \\
\hline
\end{tabular}

Tabel 2. Skor rubrik setiap kelompok

\begin{tabular}{|c|c|c|c|}
\hline Kelompok & \multicolumn{2}{|c|}{ Presentasi } & Investigasi \\
\hline & I & II & \\
\hline 1 & 2 & 3 & 4 \\
\hline 2 & 2 & 2 & 3 \\
\hline 3 & 2 & 3 & 3 \\
\hline 4 & 3 & 4 & 3 \\
\hline 5 & 3 & 4 & 4 \\
\hline 6 & 3 & 4 & 3 \\
\hline
\end{tabular}

Pretest dan postest yang diberikan dianalisis menggunakan uji t. Berdasarkan hasil uji normalitas diperoleh hasil bahwa gain score komunikasi matematis dan pemecahan masalah berdistribusi normal (Tabel 3). Hasil uji 
homogenitas varians diperoleh bahwa gain score komunikasi dan pemecahan masalah mempunyai kesamaan varians (Tabel 4).

Tabel 3. Hasil uji normalitas untuk setiap kelompok

\begin{tabular}{|l|c|c|c|}
\hline \multicolumn{1}{|c|}{ Kelompok } & Perlakuan & $\mathbf{L}_{\text {hitung }}$ & $\mathbf{L}_{\text {tabel }}$ \\
\hline Gain score Komunikasi Matematis & PBL & 0,102 & 0,1367 \\
\hline & Biasa & 0,097 & 0,1497 \\
\hline Gain score Pemecahan Masalah & PBL & 0,102 & 0,1367 \\
\hline & Biasa & 0,097 & 0,1497 \\
\hline
\end{tabular}

Tabel 4. Hasil uji homogenitas varians

\begin{tabular}{|l|c|c|}
\hline \multicolumn{1}{|c|}{ Kelompok } & $\chi_{\text {hitung }}^{2}$ & $\chi_{\text {tabel }}^{2}$ \\
\hline Gain score komunikasi matematis & 1,06 & 3,84 \\
\hline Gain score pemecahan masalah & 3,63 & 3,84 \\
\hline
\end{tabular}

Berdasarkan hasil perhitungan uji hipotesis untuk tiap kelompok diperoleh bahwa kemampuan komunikasi matematis dengan menggunakan PBL tidak lebih baik daripada pembelajaran biasa dan kemampuan pemecahan masalah pada PBL lebih baik daripada pembelajaran biasa (Tabel 5).

Tabel 5. Hasil uji hipotesis untuk komunikasi matematis dan pemecahan masalah

\begin{tabular}{|l|c|c|}
\hline \multicolumn{1}{|c|}{ Kelompok } & $\mathbf{t}_{\text {hitung }}$ & $\mathbf{t}_{\text {tabel }}$ \\
\hline Gain score komunikasi matematis & 0,0712 & 1,96 \\
\hline Gain score pemecahan masalah & 5,1452 & 1,96 \\
\hline
\end{tabular}


Hal ini bertentangan dengan hipotesis awal penelitian yaitu kemampuan komunikasi mahasiswa yang pembelajarannya menggunakan model PBL lebih baik dari pembelajaran secara biasa. Problem Based Learning memang memfasilitasi kemampuan komunikasi mahasiswa akan tetapi lebih banyak memberikan sarana untuk melatih kemampuan pemecahan masalah.

Sesuai teori yang menyatakan bahwa "pembelajaran yang menggunakan model PBL mempunyai dua tahap inti, yaitu analisis pemecahan masalah secara kolabotarif dan belajar mandiri" (Paulina dkk, 2001). Seperti definisi PBL yang dikemukakan oleh Ronnis (2000) yaitu

PBL is a curriculum development and instructional system that simultaneously develops both problem solving strategies and disciplinary knowledge bases and skills by placing students in the active role of problemsolvers confronted with an ill-structured problem that mirros real-world problems".

Soal komunikasi pada topik Statistika Deskriptif dalam bentuk interpretasi data ke penyajian grafik. Soal ini cukup mudah untuk dipahami oleh mahasiswa baik yang pembelajarannya menerapkan PBL maupun pembelajaran biasa. Alasan pembuatan soal komunikasi matematis dalam bentuk penyajian secara grafik berdasarkan definisi kemampuan komunikasi menurut Hari Suderajat (2003) yaitu "kecakapan menyampaikan informasi pada orang lain melalui bahasa lisan atau simbolsimbol tertulis, termasuk chart, peta atau alat demonstrasi lainnya”.

Pada pembelajaran dengan model PBL proses komunikasi masih menunggu arahan dan bimbingan dosen. Sikap individual mahasiswa masih dominan, karena mahasiswa belum terbiasa mengemukakan pendapat dan menghargai pendapat teman dan cenderung bertahan walau belum tentu benar jawabannya.

Hal ini telah diungkapkan oleh (Paulina dkk, 2001) sebagai salah satu kelemahan dari PBL yaitu "sejauh ini, setiap mahasiswa berasumsi bahwa mereka hanya penerima pasif dari informasi yang disampaikan dosen. Asumsi ini tumbuh berdasarkan pengalaman belajar yang dialami mereka dalam jenjang pendidikan sebelumnya. Ketika mereka berpartisipasi dalam 
PBL, peran yang dituntut adalah berbeda. Seringkali hal ini menjadi kendala bagi mahasiswa pemula". Jadi dapat dikatakan bahwa hal-hal di ataslah yang merupakan penyebab terjadinya hasil belajar untuk kemampuan komunikasi mahasiswa yang diajar dengan model PBL tidak lebih baik daripada dengan pembelajaran secara biasa.

Proses pelaksanaan pembelajaran dengan PBL, yaitu: Tahap 1 mahasiswa berdiskusi di dalam kelompoknya untuk menentukan permasalahan yang ada pada worksheet., Tahap 2 mahasiswa menuliskan permasalahan dengan bahasa sendiri. Tahap 3 mahasiswa mengidentifikasi informasi dengan melakukan percobaan atau membaca literatur yang relevan dengan masalah, Tahap 4 mahasiswa mencari informasi tambahan mengenai pembelajaran pada hari itu melalui berbagai sumber. Tahap 5 mahasiswa mengembangkan solusi yang mungkin dari masalah melalui kegiatan penemuan secara berkelompok serta merujuk pada bacaan yang terkait dengan penyelesaian masalah. Tahap 6 masing-masing kelompok mengkaji ulang solusi yang diperoleh dan membuat laporan pemecahan masalahnya. Tahap 7 dosen meminta kelompok untuk menyajikan laporannya ke depan kelas. Kelompok lain boleh memberikan pendapat dan menceritakan hasil temuan kelompok masing-masing.

Setiap pembelajaran dengan PBL selalu diawali dengan permasalahan. Tahapan proses pemecahan masalah digunakan sebagai kerangka atau panduan dalam proses pembelajaran PBL (Paulina dkk, 2001). Pada PBL, mahasiswa terlatih untuk memecahkan masalah. Sesuai teori "latihan memegang peranan penting, lebih banyak latihan dan ulangan maka akan lebih lama pengalaman dan pengetahuan itu tinggal dalam kesadaran dan ingatan seseorang" (Oemar Hamalik, 1995).

Pada PBL mahasiswa memecabkan masalah dengan melakukan percobaan dan invesitigasi melalui bacaan. Hal ini sejalan dengan "impelementasi empat pilar pendidikan UNESCO dalam pembelajaran matematika terlihat dalam pembelajaran dan penilaian yang sifatnya learning to know (fakta, skills, konsep, dan prinsip), learning to do (doing mathematics), learning to be (enjoy mathematics), dan learning to live together (cooperative learning in mathematics)" (Depdiknas, 2007). 
Pada pembelajaran biasa dosen menyajikan permasalahan dalam bentuk contoh soal dan cara untuk menyelesaikan masalah dijelaskan oleh dosen kemudian masalah lain disajikan kembali dalam bentuk latihan. Mahasiswa terkendala untuk menyelesaikan masalah jika yang ditanya berbeda dengan contoh soal. Pembelajaran biasa menurut Depdiknas (2003) mempunyai ciri-ciri pembelajaran tidak memperhatikan pengalaman siswa, pembelajaran abstrak dan teoritis serta penilaiannya hanya ditentukan oleh tes bukan pada penilaian proses belajar.

Dalam pembelajaran yang mengakomodir pemecahan masalah, mahasiswa dilatih untuk berpikir divergen/kreatif dalam usaha mencetuskan sebanyak mungkin gagasan terhadap suatu masalah. Selain itu mahasiswa dilatih untuk berpikir secara konvergen dengan menggunakan penalaran logis-kritis dalam mempertimbangkan atau merumuskan jawaban yang paling tepat. Sehingga dengan berkembangnya kemampuan pemecahan masalah mahasiswa diharapkan dapat membangun pengetahuan matematis baru, memecahkan masalah baik yang terdapat dalam matematika, maupun konteks lain dengan menerapkan berbagai strategi yang cocok serta mampu merefleksi proses-proses yang telah dilakukan dalam memecahkan masalah. Jadi dapat dikatakan bahwa hal-hal di ataslah yang merupakan penyebab terjadinya hasil belajar untuk pemecahan masalah mahasiswa yang diajar dengan model PBL lebih baik daripada dengan pembelajaran secara biasa.

\section{Kesimpulan}

Model problem based learning lebih sesuai untuk meningkatkan kemampuan pemecahan masalah dan kurang tepat untuk kemampuan komunikasi matematis. Instrumen penilaian selama pembelajaran seperti worksheet, rubrik selain untuk mengukur kinerja kelompok agar dapat juga mengukur kemampuan mahasiswa secara individu. Soal tes untuk mengukur kemampuan komunikai matematis dan pemecahan masalah dapat diperbanyak item soalnya agar dapat lebih detil mengukur setiap indikator. 


\section{Daftar Pustaka}

2007. Kajian kebijakan kurikulum mata pelajaran matematika. Badan Penelitian dan Pengembangan Pusat Kurikulum.

Departemen Pendidikan Nasional. 2003. Kurikulum berbasis kompetensi. Jakarta: Depdiknas.

Dina Mellita. 2008. Metode pembelajaran peer teaching dan problem based learning untuk memotivasi sosialisasi dalam kelas (pada pembelajaran statistika). Jurnal Ilmiah Bina Edukasi, 1(2), 87-98.

Firdaus. 2005. Melalui pembelajaran dalam kelompok kecil tipe team assisted individualization (TAI) dengan pendekatan berbasis masalah (eksperimen pada salah satu SMA di Bandung). Tesis tidak dipublikasikan. Bandung: UPI

Hari Suderajat. 2003. Implementasi kurikulum berbasis kompetensi (KBK). Jakarta: Depdiknas.

Oemar Hamalik. 1995. Kurikulum dan pembelajaran. Jakarta: Bumi Aksara.

Paulina Pannen dkk. 2001. Konstruktivisme dalam pembelajaran. Jakarta: PAUPPAI, Universitas Terbuka.

Ronnis, Diane. 2000. Problem-based learning for math and science:integrating inquiry and the internet. Illinois: Skylight Professional Development.

Wagiran. 2007. Peningkatan keaktivan mahasiswa dan reduksi miskonsepsi melaluipendekatan problem based-learning. Jurnal Kependidikan, 37(1), $1-22$. 